\title{
Pengaruh Makro Ekonomi dan Mikro Ekonomi Terhadap Profitabilitas Pada BPR Syariah di Indonesia
}

\author{
Yulvista Galuh Kirana', Diyah Santi Hariyani², Putri Oktovita Sari ${ }^{3}$ \\ Program Studi Manajemen, Universitas PGRI Madiun ${ }^{1,2,3 \text {, }}$
}

Email korespondensi: yulvistagaluhkirana@gmail.com¹ㅎiyah.santi@unipma.ac.id²; putrioktovita@gmail.com ${ }^{3}$

Received: 26 Aug 2021 Reviewed: 30 Aug 2021 Accepted: 20 Sep 2021 Published: 31 Oct 2021

\begin{abstract}
Financial performance is a proof of success obtained by a bank in carrying out its business activities. The purpose of this study is to empirically examine the effect of inflation, interest rates, CAR, FDR, NPF, BOPO on profitability. By using purposive sampling, there were eight Islamic People's Financing Banks (BPRS) registered with the OJK in 2017-2020 chosen to be the sample of this study. The secondary data in this study is derived from the financial data of the BPRS in the KAP publication reports and other information and profit and loss publication reports that are already available at the Financial Services Authority (OJK) and Bank Indonesia (BI). The data analysis method used multiple linear regression using SPSS Statistics 23.0. The results of the study through the t-test showed that inflation, interest rates, CAR, and NPF had no effect on profitability, while FDR and BOPO had a significant effect on profitability at BPRS. The distribution of BPRS financing is the most important thing where the main task of a bank is to collect and distribute funds. In financial managing bank must prioritize the principle of prudence in order to avoid bad loans.
\end{abstract}

Keywords: inflation, interest rate, micro economy, profitability

\begin{abstract}
ABSTRAK
Kinerja keuangan adalah sebuah bukti keberhasilan yang diperoleh oleh suatu perbankan dalam menjalankan kegiatan usahanya. Tujuan penelitian untuk menguji secara empiris pengaruh inflasi, suku bunga, KPMM, FDR, NPF, BOPO terhadap profitabilitas. Dengan teknik pengambilan purposive sampling diperoleh delapan Bank Pembiayaan Rakyat Syariah yang terdaftar di OJK tahun 2017-2020 sebagai sampel. Data sekunder dalam penelitian diperoleh dari data keuangan BPRS pada laporan publikasi KAP dan informasi lain serta laporan publikasi laba rugi yang sudah tersedia pada Otoritas Jasa Keuangan dan Bank Indonesia. Metode analisis data menggunakan regresi linier berganda menggunakan SPSS Statistik 23.0. Hasil penelitian melalui uji t menunjukkan bahwa inflasi, suku bunga, KPMM, dan NPF tidak berpengaruh terhadap profitabilitas, sedangkan FDR dan BOPO berpengaruh signifikan terhadap profitabilitas pada BPRS. Penyaluran pembiayaan BPRS merupakan hal paling utama di mana tugas utama dari sebuah perbankan adalah menghimpun dan menyalurkan dana. Perbankan dalam mengelola pembiayaan harus mengutamakan prinsip kehati-hatian agar tidak terjadi kredit macet.
\end{abstract}

Kata kunci: inflasi, suku bunga, mikro ekonomi, profitabilitas 


\section{A. PENDAHULUAN}

Kinerja keuangan mengacu pada keberhasilan bank dalam menjalankan bisnis. Menurut Tumandung, Murni, \& Baramuli (2017) kinerja keuangan mengacu pada pemeriksaan atas kemampuan bank untuk beroperasi sesuai dengan ketentuan yang berlaku. Kinerja keuangan merupakan kondisi di mana suatu perbankan pada periode tertentu yang menyangkut menghimpun dana dan menyalurkan dana. Rasio profitabilitas adalah rasio perbankan yang dapat digunakan untuk mengukur laba bersih.

Rasio profitabilitas merupakan rasio perbankan yang dapat digunakan untuk mengukur laba bersih. Profitabilitas suatu bank ini dapat diukur dengan menggunakan rasio keuangan yaitu return on asset (ROA) dan return on equity (ROE). ROA merupakan rasio yang digunakan perbankan dalam mengukur seberapa besar keuntungan yang diperoleh oleh suatu bank dalam menjalankan kegiatan usahanya. Sedangkan ROE merupakan alat analisis rasio keuangan perbankan untuk mengukur efisiensi dan profitabilitas pada perusahaan. ROE dapat dihitung menggunakan rumus yaitu laba bersih setelah pajak terhadap modal sendiri yang dikali dengan $100 \%$.

Perbankan syariah di Indonesia masih sulit berkembang. Hal ini disebabkan perlambatan kinerja perbankan syariah. Perlambatan kinerja perbankan syariah terjadi karena masalah dari penguatan modal, likuiditas, dan efisiensi pada perbankan syariah (Hastuti, 2019). Faktor utama perbankan dalam menjalankan usahanya adalah dengan mengukur kecukupan modal yang dimiliki. Bank harus mampu menunjang aktiva yang mengandung risiko. Faktor financing to deposit ratio (FDR) merupakan faktor perbankan dalam menyalurkan dana kepada nasabah dengan baik agar tidak menimbulkan kredit macet. Faktor biaya operasional dan pendapatan operasional (BOPO). Hal ini digunakan untuk perbankan dalam menjaga kelangsungan hidup lembaga keuangan.

Banyak faktor-faktor yang memengaruhi tinggi rendahnya profitabilitas yaitu faktor makroekonomi dan faktor mikroekonomi. Faktor makroekonomi dapat diukur dengan menghitung inflasi dan suku bunga. Inflasi merupakan harga barang maupun jasa yang mengalami peningkatan yang terjadi jika pembelanjaan semakin meningkat daripada penawaran barang di pasar. Suku bunga merupakan balas jasa yang akan diberikan oleh perbankan kepada nasabah dengan menggunakan prinsip syariah.

Berdasarkan penelitian yang dilakukan oleh Dodi (2020) dan Sasmita et al. (2018) menyatakan bahwa inflasi dan suku bunga berpengaruh terhadap profitabilitas. Berbeda dengan penelitian yang dilakukan Cahyani (2018) dan Setiawan \& Diansyah, (2018) memberikan hasil 
bahwa inflasi dan suku bunga tidak berpengaruh terhadap profitabilitas. Selanjutnya, faktor mikroekonomi yang dapat memengaruhi ROA di antaranya adalah kewajiban penyediaan modal minimum (KPMM), financing to deposit ratio (FDR), non performing financing (NPF), dan biaya operasional dan pendapatan operasional (BOPO). KPMM merupakan rasio untuk mengetahui besarnya jumlah aset yang dimiliki perbankan. Rasio keuangan FDR merupakan rasio yang digunakan oleh perbankan dalam mengukur penyaluran pembiayaan. Rasio NPF adalah rasio keuangan yang digunakan untuk mengukur kemampuan suatu perbankan dalam meminimalkan risiko kegagalan pengembalian kredit oleh pihak nasabah. BOPO adalah rasio yang digunakan untuk mengukur efisiensi operasional suatu perbankan. Berdasarkan penelitian yang dilakukan oleh Ningsih \& Rachmawati (2019) dan Al Iqbal \& Budiyanto (2020) KPMM, FDR, NPF, dan BOPO berpengaruh terhadap profitabilitas. Berbeda dengan penelitian Fatah \& Rahadian (2018) yang menyatakan hasil tidak ada pengaruh terhadap profitabilitas.

Perbankan syariah merupakan lembaga keuangan yang menjalankan kegiatan usahanya dengan cara menghimpun dan menyalurkan dana dari masyarakat. Penghimpunan dana dari masyarakat berupa simpanan. Salah satu bank yang dipercaya masyarakat dalam menghimpun dana adalah Bank Pembiayaan Rakyat Syariah (BPRS) yang didirikan dengan tujuan untuk dapat meningkatkan kesejahteraan ekonomi masyarakat Indonesia khususnya umat Islam, di golongan ekonomi mikro pedesaan. BPRS berkegiatan untuk mempercepat siklus ekonomi masyarakat. Tujuan penelitian ini diharapkan mampu menguji secara empiris pengaruh makroekonomi yang diwakili variabel inflasi dan suku bunga dan mikroekonomi yang diwakili dengan variabel KPMM, FDR, NPF dan BOPO berpengaruh terhadap profitabilitas secara parsial.

\section{B. TELAAH PUSTAKA}

\section{Kinerja Keuangan}

Kinerja keuangan adalah satu-satunya dasar untuk menilai kondisi keuangan perbankan berdasarkan analisis keuangan perbankan. Kinerja keuangan sebuah perbankan dapat dilihat dari berbagai variabel (Ningsih \& Rachmawati, 2019). Kinerja keuangan merupakan suatu alat ukur yang digunakan untuk menghitung seberapa banyak keuntungan yang diperoleh suatu perbankan. Kinerja keuangan merupakan pengukuran yang digunakan dalam suatu bank saat melakukan penataan di masa mendatang, agar kesalahan pada tentang waktu sebelumnya tidak terulang kembali dan agar perbankan semakin maju dan dapat bersaing dengan perbankan lain. 
Tujuan dari pengukuran kinerja keuangan perusahaan dapat mengetahui tingkat likuiditas, solvabilitas, profitabilitas, dan stabilitas.

\section{Bank Syariah}

Bank syariah bekerja dengan menghimpun anggaran serta menyalurkannya pada masyarakat lewat angsuran ataupun pembiayaan. Pembayaran dana distribusi dana diatur oleh prinsip-prinsip Islam atau syariah, dan bank-bank Islam beroperasi atas dasar bagi hasil. Kehadiran bank syariah yang menganut prinsip syariah yang melarang riba menguntungkan perekonomian Indonesia dengan memungkinkan penduduk negara yang mayoritas muslim untuk memercayakan bank syariah dengan proses pengumpulan dan penggunaan layanan bank syariah lainnya. Wajar jika eksistensi perbankan syariah sangat ideal dalam kondisi seperti ini (Siregar, 2020).

\section{Rasio Profitabilitas}

Menurut Karim dan Hanafia (2020) profitabilitas merupakan kemampuan suatu perbankan dalam menunjukkan kinerja perbankan yang mengacu pada tingkat efisiensi maupun efektivitas pengoperasian perbankan dalam mendapatkan keuntungan atau laba. Profitabilitas merupakan dimensi keahlian bank untuk mendapatkan profit dalam bentuk persentase (persen). Profitabilitas dapat ditentukan dengan membandingkan ROA dan ROE.

\section{Return On Asset (ROA)}

Rasio yang digunakan perbankan dalam mengukur kinerjanya yang akan menghasilkan laba atau keuntungan yang diperoleh perbankan terkait dengan sumber daya atau total aset, sehingga efisiensi perbankan dalam mengelola asetnya dapat terlihat dari persentase ROA. Menurut Wirnawati \& Diyani (2019) ROA dapat menunjukkan tingkat efisiensi pengelolaan aset perbankan. Apabila ROA suatu perbankan mengalami kenaikan maka bank dikatakan baik dan apabila bank mengalami penurunan laba maka bank dikatakan tidak baik atau mengalami kerugian.

\section{Inflasi}

Inflasi merupakan kenaikan umum harga benda serta pelayanan. Kenaikan harga tersebut tidak terjadi dalam satu kejadian, tetapi terjadi secara terus-menerus. Contoh dari kejadian inflasi misalnya saja harga-harga menjelang hari lebaran, hari natal, dan hari libur lainnya cenderung naik. Namun, setelah hari libur selesai harga-harga akan kembali normal atau stabil (Iqbal dan Budiyanto, 2020). Inflasi merupakan kenaikan harga benda serta pelayanan dengan cara terus-menerus sepanjang rentang waktu durasi khusus. Ketika pengeluaran melebihi pasokan barang di pasar, hal ini akan menyebabkan harga naik. 


\section{Suku Bunga}

Rasio suku bunga merupakan balas jasa yang diperuntukkan dari bank berdasarkan prinsip konvensional kepada nasabah. Kenaikan suku bunga perbankan dapat meningkatkan pembiayaan perbankan syariah. Suku bunga yang mengalami kenaikkan akan berpengaruh pada peningkatan pembiayaan perbankan syariah. Kebijakan suku bunga merupakan kebijakan moneter yang telah dikeluarkan oleh pemerintah agar bisa mendorong pertumbuhan perekonomian industri perbankan.

\section{Kewajiban Penyediaan Modal Minimum (KPMM)}

KPMM adalah rasio yang digunakan untuk menilai kinerja suatu bank, lebih tepatnya kemampuannya dalam mendukung aset-aset berisiko. Modal adalah komponen penting dari proses kewirausahaan. Jika KPPM semakin tinggi ini berarti semakin kuat kemampuan perbankan dalam menanggung risiko terjadinya pinjaman/aset produktif yang mengalami risiko (Karim \& Hanafia, 2020).

\section{Financing to Deposit Ratio (FDR)}

Rasio FDR adalah rasio total aktiva yang disalurkan oleh pihak perbankan kepada pihak nasabah terhadap modal yang dimiliki oleh perbankan. FDR memperlihatkan kemampuan perbankan di dalam memberikan simpanan kepada peminjam sekaligus membayarkan kembali kepada penyimpan dengan mengandalkan angsuran yang disalurkan sebagai sumber likuiditas.

\section{Non Performing Financing (NPF)}

NPF adalah rasio perbankan yang dibuat ketika nasabah yang gagal memenuhi kewajiban keuangan mereka ke sektor perbankan. Akibatnya, ini menghasilkan kredit yang buruk. Artinya, untuk setiap pembiayaan yang disalurkan melalui bank, pasti risiko yang ditanggung oleh perbankan syariah. Oleh karena itu, bank harus mampu mengelola pembiayaan dengan lebih baik untuk menghindari hal tersebut (Ibrahim et al. 2019).

\section{Beban Operasional dan Pendapatan Operasional (BOPO)}

BOPO adalah rasio yang digunakan untuk menilai efisiensi operasional bank. Rasio BOPO ini digunakan untuk membandingkan beban usaha dengan pendapatan usaha. Apabila rasio BOPO semakin rendah berarti ini menunjukkan manajemen perbankan semakin baik Setyowati (2019). BOPO adalah rasio perbankan untuk menghitung perbandingan antara biaya operasional dan pendapatan operasional, dengan mengukur tingkat efisiensi dan kemampuan perbankan untuk menjalankan operasionalnya. 


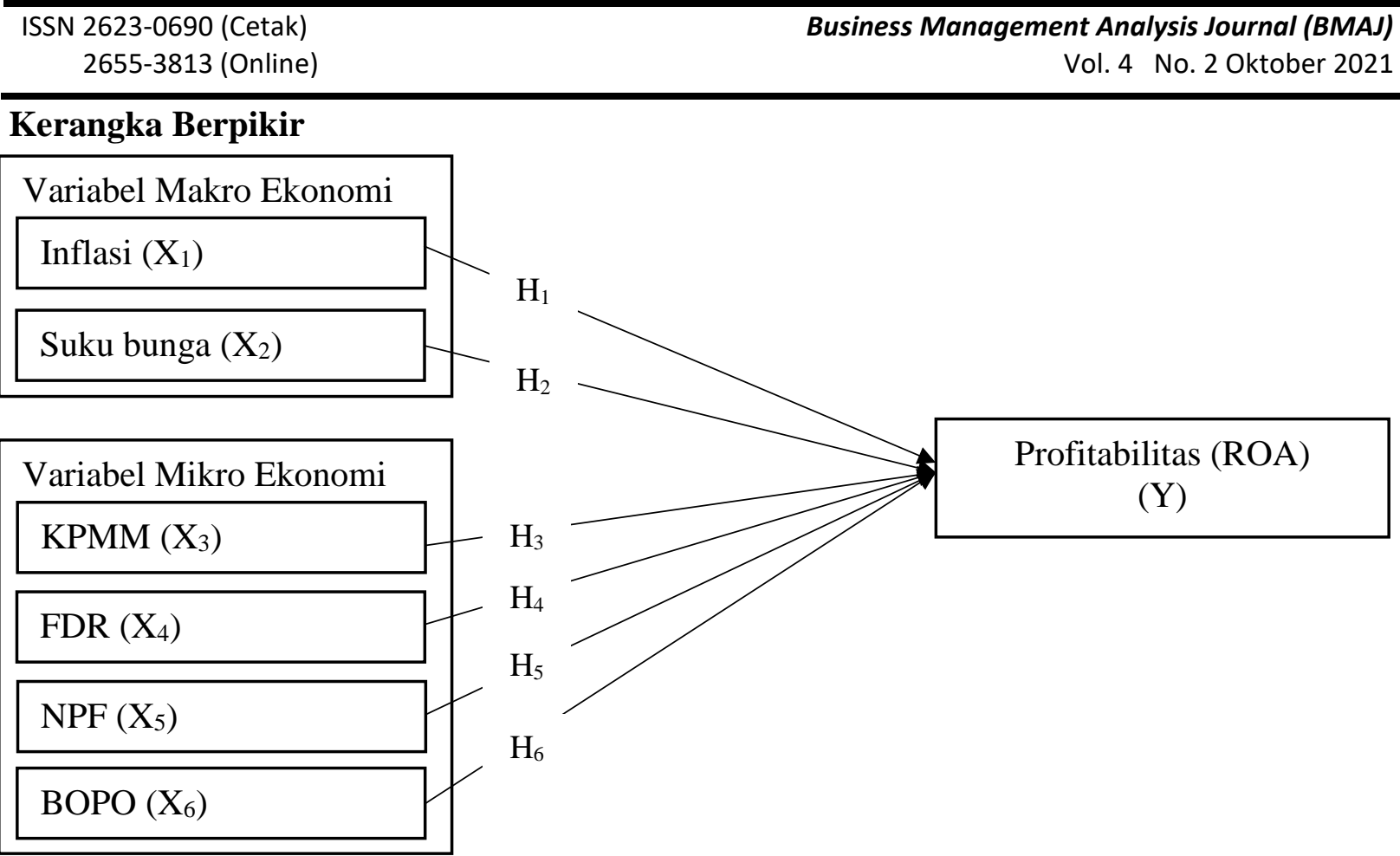

Gambar 1: Kerangka Berpikir

Sumber: Setiawan (2016)

Berdasarkan kerangka berpikir di atas maka dapat diambil hipotesis penelitian sebagai berikut:

$\mathrm{H}_{1}$ : Inflasi berpengaruh signifikan terhadap profitabilitas.

$\mathrm{H}_{2}$ : Suku bunga berpengaruh signifikan terhadap profitabilitas.

$\mathrm{H}_{3}$ : KPMM berpengaruh signifikan terhadap profitabilitas.

$\mathrm{H}_{4}$ : FDR berpengaruh signifikan terhadap profitabilitas.

$\mathrm{H}_{5}$ : NPF berpengaruh signifikan terhadap profitabilitas.

$\mathrm{H}_{6}$ : BOPO berpengaruh signifikan terhadap profitabilitas.

\section{METODE PENELITIAN}

Populasi yang digunakan dalam penelitian ini seluruh BPRS di Indonesia yang berjumlah 163. Metode yang digunakan adalah metode purposive sampling. Metode purposive sampling merupakan metode memilih sampel berdasarkan kriteria tertentu berdasarkan tujuan penelitian agar mendapatkan suatu informasi (Setiawan \& Diansya, 2018). Kemudian peneliti melakukan identifikasi di mana penentuan jumlah sampel sebanyak 8 BPRS yang terdaftar di OJK. Pengambilan sampel dilakukan selama 4 tahun yaitu 2017 sampai dengan 2020 sehingga akan menghasilkan sebanyak 32 sampel. Teknik pengukuran dalam penelitian ini menggunakan data sekunder. Data sekunder dalam penelitian diperoleh dari data keuangan BPRS pada laporan 
publikasi KAP dan informasi lain serta laporan publikasi laba rugi yang sudah tersedia pada Otoritas Jasa Keuangan (OJK) yang diperoleh melalui situs resmi www.ojk.co.id dan Bank Indonesia (BI) yang diperoleh melalui situs resmi www.bi.go.id. Dalam penelitian ini mengambil data sekunder dari OJK melalui situs resmi www.ojk.co.id dan BI melalui situs resmi www.bi.go.id.

Berdasarkan permasalahan yang diangkat dalam pembahasan penelitian ini menggunakan jenis data kuantitatif. Menurut Karim \& Hanafia (2020) penelitian kuantitatif merupakan cara untuk menguji teori-teori tertentu dengan cara meneliti apakah ada hubungan antar variabel. Dalam penelitian ini proses data menggunakan data yang tersedia pada situs resmi perbankan yang sesuai dengan laporan keuangan yang tersedia. Teknik analisis data yang digunakan dalam penelitian ini adalah statistik deskriptif, uji asumsi klasik, dan uji hipotesis. Penelitian ini menggunakan SPSS Statistik 23.0.

\section{HASIL DAN PEMBAHASAN}

\section{Hasil Uji Regresi Linier Berganda}

Berdasarkan hasil analisis regresi linier berganda yang telah diolah menggunakan aplikasi SPSS, maka persamaan regresi pada penelitian ini adalah sebagai berikut:

$\mathrm{Y}=\alpha+\mathrm{b}_{1} \mathrm{X}_{1}+\mathrm{b}_{2} \mathrm{X}_{2}+\mathrm{b}_{3} \mathrm{X}_{3}+\mathrm{b}_{4} \mathrm{X}_{4}+\mathrm{b}_{5} \mathrm{X}_{5}+\mathrm{b}_{6} \mathrm{X}_{6}+\mathrm{e}$

$\mathrm{ROA}=0,012+0,021 \mathrm{X}_{1}-0,374 \mathrm{X}_{2}-0,008 \mathrm{X}_{3}+0,011 \mathrm{X}_{4}+0,015 \mathrm{X}_{5}+0,017 \mathrm{X}_{6}+\mathrm{e}$

Persamaan regresi di atas diperoleh dari hasil output SPSS yang dapat dilihat pada tabel 1 .

Tabel 1: Regresi Linier Berganda

\begin{tabular}{|c|c|c|c|c|c|c|}
\hline \multicolumn{7}{|c|}{ Coefficients $^{a}$} \\
\hline & \multirow[t]{2}{*}{ Model } & \multicolumn{2}{|c|}{$\begin{array}{c}\text { Unstandardized } \\
\text { Coefficients }\end{array}$} & \multirow{2}{*}{$\begin{array}{c}\text { Standardized } \\
\text { Coefficients } \\
\text { Beta } \\
\end{array}$} & \multirow[t]{2}{*}{$\mathbf{t}$} & \multirow[t]{2}{*}{ Sig. } \\
\hline & & B & Std. Error & & & \\
\hline \multirow[t]{7}{*}{1} & (Constant) & .012 & .025 & & .470 & .639 \\
\hline & Inflasi & .021 & .192 & .010 & .109 & .913 \\
\hline & Suku bunga & -.374 & .540 & -.060 & -.692 & .490 \\
\hline & KPMM & -.008 & .025 & -.029 & -.299 & .765 \\
\hline & FDR & .011 & .006 & .199 & 2.019 & .046 \\
\hline & NPF & .015 & .016 & .080 & .915 & .362 \\
\hline & BOPO & .017 & .007 & .220 & 2.321 & .022 \\
\hline
\end{tabular}

a. Dependent Variable: ROA

Sumber: Hasil output SPSS, data diolah (2021) 
Berdasarkan output SPSS pada tabel 1, uji statistik secara parsial menunjukkan bahwa inflasi tidak berpengaruh signifikan terhadap profitabilitas. Hal ini dapat dilihat di mana menunjukkan nilai signifikan sebesar 0,913. Berdasarkan uji statistik menunjukkan bahwa suku bunga tidak berpengaruh signifikan terhadap profitabilitas. Hal ini dapat dilihat nilai signifikan sebesar 0,490. Berdasarkan uji statistik menunjukkan bahwa KPMM tidak berpengaruh signifikan terhadap profitabilitas. Berdasarkan uji statistik menunjukkan bahwa FDR berpengaruh positif dan signifikan terhadap profitabilitas. Hal ini dapat dilihat dari FDR yang memiliki nilai sig $=0,04<0,05$. Berdasarkan uji statistik menunjukkan bahwa NPF tidak berpengaruh signifikan terhadap profitabilitas. Hal ini dapat dilihat dari NPF yang memiliki nilai signifikan 0,36>0,05. Berdasarkan uji statistik menunjukkan bahwa BOPO berpengaruh positif dan signifikan terhadap profitabilitas. Hal ini dapat dilihat dari NPF yang memiliki nilai signifikan $0,02<0,05$.

Tabel 2: Hasil Uji Determinasi $\left(\mathrm{R}^{2}\right)$

\begin{tabular}{lcccr}
\hline \multicolumn{4}{c}{ Model Summary } \\
\hline Model & $\boldsymbol{R}$ & $\boldsymbol{R}$ & $\begin{array}{l}\text { Adjusted } \\
\text { Square }\end{array}$ & $\begin{array}{r}\text { R Square } \\
\text { Std. Error of } \\
\text { the Estimate }\end{array}$ \\
\hline 1 & $.358^{\mathrm{a}}$ & .128 & .085 & .0148397 \\
\hline \multicolumn{2}{l}{ Predictors: (Constant), BOPO, KPMM, Suku bunga, } \\
NPF, Inflasi, FDR \\
b. Dependent Variable: ROA
\end{tabular}

Sumber: Hasil output SPSS, data diolah (2021)

Berdasarkan tabel 2 diperoleh hasil analisis koefisien determinasi regresi linier berganda dengan nilai $\mathrm{R}^{2}$ (adjusted $R$ square) 0,085, artinya pengaruh dari variabel independen yaitu makroekonomi (inflasi dan suku bunga) dan mikroekonomi yaitu (KPMM, FDR, NPF dan BOPO) terhadap variabel dependen yaitu profitabilitas (ROA) sebesar 8,5\% sedangkan sisanya 91,5\% dipengaruhi oleh variabel lain yang tidak diteliti pada penelitian ini. Hal ini nilai adjusted $R$ square memiliki nilai persentase rendah karena ada enam variabel independen dan yang berpengaruh signifikan terhadap variabel dependen hanya ada dua variabel sedangkan empat variabel lainnya tidak berpengaruh dan signifikan. 


\section{Pembahasan}

\section{Pengaruh Inflasi Terhadap Profitabilitas}

Berdasarkan tabel 1 menggunakan analisis regresi linier berganda dapat disimpulkan bahwa inflasi tidak memiliki pengaruh terhadap profitabilitas. Alasannya adalah yang menjadi tolak ukur di mana kondisi inflasi yang terus meningkat ini akan mencerminkan kenaikan suatu barang-barang yang menjadikan nilai peredaran uang dapat berkurang dan menyebabkan harga-harga semakin mengalami peningkatan (Sasmita et al. 2018). Hasil penelitian selama tahun 2017-2020 inflasi tidak berpengaruh terhadap profitabilitas. Inflasi dan profitabilitas cenderung memiliki hubungan negatif terutama jika rasio modal tinggi karena biaya cenderung meningkat daripada pendapatan sistem teknologi yang digunakan dan masalah yang dialami oleh pengguna sistem. Hasil penelitian ini sama dengan yang dilakukan oleh Cahyani (2018) dan Setiawan \& Diansyah (2018) yang menyatakan bahwa inflasi tidak berpengaruh signifikan terhadap profitabilitas. Berbeda dengan penelitian yang dilakukan oleh Khotijah, Suharti, \& Yudhawati (2020) dan Alhayria, Azaluddin, \& Mahmuda (2019) yang menyatakan bahwa inflasi mempunyai pengaruh terhadap profitabilitas.

\section{Pengaruh Suku Bunga Terhadap Profitabilitas}

Hasil dalam penelitian ini menyatakan bahwa suku bunga tidak berpengaruh terhadap profitabilitas hal ini berarti semakin meningkat bunga kredit di perbankan maka bank akan kesulitan dalam menyalurkan dananya kepada masyarakat. Hal ini yang menjadikan pendapatan paling utama dari sebuah usaha perbankan yang semakin rendah maka profitabilitasnya juga akan berdampak yaitu mengalami penurunan. Berbeda dengan penelitian yang dilakukan oleh Fitriana \& Musdholifah, (2017) dan Alhayria et al. (2019) yang menyatakan bahwa suku bunga mempunyai pengaruh signifikan terhadap profitabilitas.

\section{Pengaruh KPMM Terhadap Profitabilitas}

Berdasarkan hipotesis ketiga yang telah diajukan dalam penelitian ini diuji dengan menggunakan analisis regresi linier berganda dapat disimpulkan bahwa KPMM tidak memiliki pengaruh terhadap profitabilitas. Hal ini disebabkan karena bank belum mampu mengelola modal yang ada sehingga mengakibatkan profitabilitas mengalami penurunan. Bank yang tidak mampu mengelola dananya dengan baik akan mengakibatkan melambatnya proses kegiatan usaha dan penurunan laba pada bank. Bank yang tidak mampu beroperasi secara efektif akan menyebabkan menurunnya laba perbankan. Modal merupakan faktor penggerak utama pengembangan suatu bisnis, sehingga semakin rendah KPMM maka akan semakin rendah juga profitabilitas yang dimiliki bank begitu juga sebaliknya. Berbeda dengan penelitian yang 
dilakukan oleh Zubair \& Hartono (2019) serta Almunawwaroh \& Marliana (2018) yang menyatakan hasil bahwa variabel KPMM mempunyai pengaruh terhadap variabel profitabilitas.

\section{Pengaruh FDR Terhadap Profitabilitas}

Berdasarkan hipotesis keempat yang telah diajukan dalam penelitian ini diuji dengan menggunakan analisis regresi linier berganda dapat disimpulkan bahwa FDR memiliki pengaruh terhadap profitabilitas. Dalam penelitian ini kenaikan FDR akan memengaruhi kenaikan nilai profitabilitas. Suatu bank yang dapat menyalurkan kreditnya dalam batas yang telah ditentukan dan disepakati oleh kedua belah pihak akan mendapatkan tambahan pendapatan yang dibebankan kepada nasabah. Hal ini dapat menaikan laba yang diperoleh suatu perbankan. Perbankan yang mampu menyalurkan dananya dengan efisien akan memberikan keuntungan kepada pihak bank. Hasil penelitian yang telah dilakukan sejalan dengan Maemunah \& Yanti (2016) yang menyatakan hasil bahwa variabel FDR berpengaruh signifikan terhadap profitabilitas.

\section{Pengaruh NPF Terhadap Profitabilitas}

Hasil penelitian ini menyatakan bahwa NPF tidak berpengaruh terhadap profitabilitas disebabkan nilai rata-rata pada BPRS memiliki nilai yang kecil. Faktor lain yang menyebabkan variabel NPF tidak berpengaruh terhadap profitabilitas adalah karena adanya tingkat pengelolaan operasional BPRS yang baik. Hal ini yang akan mengakibatkan NPF pada suatu perbankan menjadi tidak berpengaruh terhadap profitabilitas disebabkan bertambahnya NPF dibarengi dengan adanya efisiensi pengelolaan kinerja operasional bank. Berbeda dengan penelitian yang dilakukan oleh Peling \& Sedana (2018) yang menyatakan hasil bahwa variabel NPF mempunyai pengaruh terhadap variabel profitabilitas.

\section{Pengaruh BOPO Terhadap Profitabilitas}

Hasil penelitian ini menunjukkan bahwa variabel BOPO berpengaruh signifikan terhadap profitabilitas disebabkan karena jika suatu angka BOPO mengalami penurunan maka akan semakin baik kinerja manajemen perbankan. Suatu bank dalam menjalankan operasionalnya akan menggunakan sumber daya yang ada di suatu perbankan ini akan mengakibatkan bank akan lebih efisien dan profit yang diperoleh akan semakin besar. BOPO memiliki tujuan yang mampu untuk meminimalkan risiko operasional suatu perbankan yang mengenai ketidakpastian suatu kegiatan perbankan. Hasil ini sejalan dengan penelitian yang dilakukan oleh Huda et al. (2019) menyatakan hasil bahwa variabel BOPO yang secara parsial berpengaruh terhadap profitabilitas. 


\section{E. KESIMPULAN DAN SARAN}

\section{Kesimpulan}

Berdasarkan hasil penelitian didapatkan beberapa kesimpulan. Secara parsial inflasi tidak berpengaruh terhadap profitabilitas pada BPRS yang ada di Indonesia tahun 2017 sampai dengan 2020. Secara parsial suku bunga tidak berpengaruh terhadap profitabilitas pada BPRS yang ada di Indonesia tahun 2017 sampai dengan 2020. Secara parsial KPMM tidak berpengaruh terhadap profitabilitas pada BPRS yang ada di Indonesia tahun 2017 sampai dengan 2020. Secara parsial FDR berpengaruh terhadap profitabilitas pada BPRS yang ada di Indonesia tahun 2017 sampai dengan 2020. Secara parsial NPF tidak berpengaruh terhadap profitabilitas pada BPRS yang ada di Indonesia tahun 2017 sampai dengan 2020. Secara parsial BOPO berpengaruh terhadap profitabilitas pada BPRS yang ada di Indonesia tahun 2017 sampai dengan 2020.

\section{Saran}

Bagi penelitian sejenis dapat dilakukan dengan menambahkan variabel lain di luar variabel yang telah diteliti seperti variabel NIM, LAD, DPK, PDB, dan nilai tukar rupiah. Selain itu, penelitian terhadap dampak covid-19 terhadap profitabilitas jangka panjang BPRS juga dapat dilakukan.

\section{DAFTAR PUSTAKA}

Al Iqbal, M. H., \& Budiyanto, I. (2020). Analisis Pengaruh Kewajiban Penyediaan Modal Minimum (KPMM), Beban Operasional Pendapatan Operasional (BOPO), Financing To Deposit Ratio (FDR), dan Inflasi Terhadap Return On Asset (ROA) Pada Bank Umum Syariah di Indonesia Periode 2016-2019. Malia: Journal of Islamic Banking and Finance, 4(1), 1-11. https://doi.org/10.21043/malia.v4i1.6887

Alhayria, Azaluddin, \& Mahmuda, D. (2019). Pengaruh Inflasi Dan Suku Bunga Terhadap Return On Asset (ROA) Bank Yang Listing Pada BEI. Jurnal Ilmiah Mahasiswa Fakultas Ekonomi UM.Buton, 1(1), 33-44. Retrieved from http://journal.feb.unmul.ac.id/index.php/JIEM/article/view/1381

Almunawwaroh, M., \& Marliana, R. (2018). Pengaruh CAR,NPF Dan FDR Terhadap Profitabilitas Bank Syariah Di Indonesia. Amwaluna: Jurnal Ekonomi Dan Keuangan Syariah, 2(1), 1-18. https://doi.org/10.29313/amwaluna.v2i1.3156

Bank Indonesia. (2019). Retrieved December 8, 2020, from https://bi.go.id

Cahyani, Y. T. (2018). Pengaruh Inflasi, Suku Bunga (BI Rate), Produk Domestik Bruto (PDB) Terhadap ROA (Studi Pada Bank Pembiayaan Rakyat Syariah (BPRS) di Indonesia Tahun 2009-2016). Jurnal Ekonomi Dan Perbankan Syariah, 5(1), 59-83. 
Dodi. (2020). Analisis Pengaruh Inflasi dan Produk Domestik Bruto Terhadap Profitabilitas (Studi Kasus Pada Bank Umum Syariah Di Indonesia). Indonesian Journal Of Strategic Management Vol, 3(2), 1-7.

Fatah, S.S., \& Rahadian, D. (2018). Pengaruh Capital Adequacy Ratio (CAR), Non Performing Financing (NPF), Financing To Deposit Ratio (FDR), Dan Efisiensi Operasional (BOPO) Terhadap Profitabilitas (ROA) Perbankan. E-Proceeding of Management, 5(1), 268-275.

Fitriana, S., \& Musdholifah. (2017). Pengaruh faktor internal dan bi rate terhadap profitabilitas bank umum syariah periode 2012-2015. Jurnal Ilmu Manajemen, 5(3), 115 .

Hastuti, R. K. (2019). Perbankan Syariah Masih Sulit Bersaing Dengan Konvensional. Retrieved December 10, 2020, from https://googleweblight.com/sp?u=https://www.cnbcindonesia.com/syariah/2019060713 3414-29-77037/perbankan-syariah-masih-sulit-bersaing-dengankonvensional\&grqid=1HvmqSbR\&hl=jv-ID

Huda, N., Amin, M., \& Mahsuni, A. W. (2019). Pengaruh DPK, NPL Dan BOPO Terhadap Profitabilitas Perbankan Yang Terdaftar Di Bursa Efek Indonesia. Jurnal Ilmiah Riset Akuntansi, 8, 13-26.

Ibrahim, M., Nuzula, N. F., \& Nurlaily, F. (2019). Pengaruh Kecukupan Modal, Fungsi Intermediasi, Pembiayaan Bermasalah, Biaya Operasi, Dan (Studi Pada Bank Syariah Di Indonesia Periode 2010-2017). Jurnal Administrasi Bisnis, 72(2), 175-185.

Karim, A., \& Hanafia, F. (2020). Analisis CAR, BOPO, NPF, FDR, NOM, dan DPK Terhadap Profitabilitas (ROA) Pada Bank Syariah Di Indonesia. Jurnal Manajemen Dan Bisnis, 2(1), 36-46. https://doi.org/10.30812/target.v2i1.697

Khotijah, N. Z., Suharti, T., \& Yudhawati, D. (2020). Pengaruh Tingkat Suku Bunga dan Inflasi Terhadap Profitabilitas, Manager Jurnal Ilmu Manajemen, 3(1), 40-47.

Maemunah, M., \& Yanti. (2016). Pengaruh NPF, BOPO Dan FDR Terhadap Profitabilitas Perbankan Syariah (Studi Kasus Pada Perbankan Syariah Di Indonesia Periode 20122016). Buana Akuntansi, 5(1), 79-92.

Ningsih, W. F., \& Rachmawati, L. (2019). Faktor-Faktor yang Mempengaruhi Profitabilitas pada Bank Pembiayaan Rakyat Syariah di Jawa Timur. JABE (Journal of Applied Business and Economic), 5(4), 365-383. https://doi.org/10.30998/jabe.v5i4.4185

Otoritas Jasa Keuangan. (2019). Retrieved December 9, 2020, from https://www.ojk.go.id/id/kanal/syariah/data-dan-statistik/statistik-perbankansyariah/Pages/Statistik-Perbankan-Syariah---Desember-2019.aspx

Peling, I. A. A., \& Sedana, I. B. P. (2018). Pengaruh LDR, NPL, Dan BOPO Terhadap Profitabilitas Pada PT. BPD Bali Periode Tahun 2009-2016. E-Jurnal Manajemen Universitas Udayana, 7(6), 2999-3026. https://doi.org/10.24843/EJMUNUD.2018.v07.i06.p06

Sasmita, D., Andriani, S., \& Ilman, A. H. (2018). Analisis Pengaruh Inflasi, Suku Bunga Bi, Nilai Tukar Rupiah Terhadap Profitabilitas (Studi Kasus Pada Bank Yang Terdaftar Di Bei Periode 2011-2015). Jurnal Ekonomi Dan Bisnis Indonesia, 3(1), 1-7. 
https://doi.org/10.37673/jebi.v3i1.379

Setiawan, A. (2016). Pengaruh Tingkat Kesehatan Bank Terhadap Return On Asset. Jurnal Lentera Akuntansi, 2(2), 1-13.

Setiawan, S., \& Diansyah. (2018). Pengaruh CAR, BOPO, NPL, Inflasi Dan Suku Bunga Terhadap Profitabilitas Pada Bank Umum Konvensional Yang Terdaftar Di Bursa Efek Indonesia. Online Internasional \& Nasional, 6(2), 1-17.

Setyowati, D. H. (2019). Pengaruh Efisiensi Operasional Terhadap Return On Assets Pada Bank Umum Syariah Di Indonesia. Masharif Al-Syariah: Jurnal Ekonomi Dan Perbankan Syariah, 4(2), 39-53.

Siregar, P. A. (2020). Risiko Keuangan dan Pengaruhnya Terhadap Profitabilitas Bank Syariah Di Indonesia. Ekonomi Islam, 5(1), 120-141.

Tumandung, C. O., Murni, S., \& Baramuli, D. N. (2017). Analisis Pengaruh Kinerja Keuangan Terhadap Harga Saham Pada Perusahaan Makanan dan Minuman Yang Terdaftar Di BEI Periode 2011-2015. Jurnal Riset Ekonomi, Manajemen, Bisnis Dan Akuntansi, 5(2), 1728-1737.

Wirnawati, M., \& Diyani, L. A. (2019). Pengujian CAR, NPF, FDR, dan BOPO Terhadap Profitabilitas Pada Bank Umum Syariah. Jurnal Mahasiswa Bina Insani, 4(1), 69-80.

Zubair, A.N., \& Hartono, T. (2019). Analisis Pengaruh Kewajiban Penyediaan Modal Minimum (KPMM), Non Performing Financing (NPF), Financing To Deposit Ratio (FDR), Dan Biaya Operasional Terhadap Pendapatan Operasional (BOPO) Terhadap Return On Assets (ROA) Pada Bank Umum Syariah Di Indonesia. Sains Ekonomi Dan Perbankan Syariah, 9(1), 16-30. 